\title{
Neuroprotective Effects of Trolox in Global Cerebral Ischemia in Gerbils
}

\author{
Sangeetha GuPTA and Shyam Sunder SHARMA* \\ Department of Pharmacology and Toxicology, National Institute of Pharmaceutical Education and Research (NIPER); \\ Sector-67, S.A.S. Nagar, Punjab-160062, India. $\quad$ Received November 18, 2005; accepted February 16, 2006
}

\begin{abstract}
Stroke is a third leading cause of death and oxygen free radicals have been shown to be involved in its pathophysiology. In the present study, we have investigated neuroprotective potential of trolox, a free radical scavenger in bilateral carotid arteries occlusion $(5 \mathrm{~min})$ model of global cerebral ischemia in Mongolian gerbils. Gerbils were treated with trolox $(3,10$ or $30 \mathrm{mg} / \mathrm{kg}$, i.p.) $30 \mathrm{~min}$ prior to occlusion. There was a significant increase in neurological symptoms and locomotor activity in ischemic animals as compared with the sham-operated animals. These effects were attenuated by trolox $30 \mathrm{mg} / \mathrm{kg}$, i.p. Significant increase in the number of the surviving neurons in the hippocampal CA1 pyramidal region was observed in ischemic animals treated with trolox $30 \mathrm{mg} / \mathrm{kg}$, i.p. There was significant increase in the level of malondialdehyde (MDA) in ischemic animals indicating oxidative stress. Elevated levels of MDA in ischemic animals $\left(25.79 \pm 3.34 \mu_{\mathrm{M}} / \mathrm{mg}\right.$ of protein) were reduced $(16.43 \pm 3.32 \mu \mathrm{M} / \mathrm{mg}$ of protein) and $(8.98 \pm 0.89 \mu \mathrm{M} / \mathrm{mg}$ of protein) by trolox 10 and $30 \mathrm{mg} / \mathrm{kg}$, i.p., respectively. This study demonstrates the neuroprotective potential of trolox in global cerebral ischemia in gerbils.
\end{abstract}

Key words trolox; global cerebral ischemia; gerbil; reactive oxygen species; hippocampus

Stroke is the third leading cause of death and a major cause of long-term disability in industrialized countries. Dramatic reduction of oxygen in stroke may lead to ischemia of the whole brain (global ischemia) or of defined cerebral territories (focal ischemia) depending on the cerebral artery occluded. ${ }^{1)}$ Global cerebral ischemia is commonly an outcome of a range of clinical conditions, which comprises cardiac arrest, closed head injury, coronary artery bypass surgery etc. The most affected brain area as a consequence of global ischemia is CA1 neurons of the hippocampus. Neuronal death in global ischemia precedes $1-3 \mathrm{~d}$ after insult, a process referred as delayed neuronal death. ${ }^{2-4)}$

The pathophysiological mechanisms leading to neuronal injury in ischemic stroke are complex and multifactorial. Ischemia induced brain damages are accompanied by biochemical alterations and neurological sequelae. ${ }^{1)}$ There are substantial experimental evidences that reactive oxygen species (ROS) are produced in the brain during ischemia and reperfusion injury. ${ }^{5)}$ ROS such as superoxide radical, hydroxyl radical and hydrogen peroxide contributes to ischemic brain damage. ${ }^{5)}$ Superoxide can react with nitric oxide to form peroxynitrite, a potent oxidant. It has been proposed that many of the toxic effects of nitric oxide are due to the generation of peroxynitrite. Peroxynitrite can directly react with target biomolecules like DNA, protein, via one or two electron oxidations. ${ }^{5-7)}$

Antioxidants such as (-)-epigallocatechin gallate, melatonin, curcumin, FeTMPyP and FeTPPS have been demonstrated to ameliorate neuronal damage in cerebral ischemic reperfusion injury. ${ }^{3,8-11)}$ Antioxidant activity of trolox (6-hydroxy-2,5,7,8-tetramethyl chroman-2-carboxylic acid) a cellpermeable, water-soluble derivative of vitamin $\mathrm{E}$ has been established in vitro and in vivo conditions. ${ }^{12-15)}$ However its neuroprotective effects have not been investigated in global cerebral ischemia. Therefore, in the present study, the neuroprotective potential of trolox was investigated in bilateral carotid artery occlusion induced global cerebral ischemia in Mongolian gerbils.

\section{MATERIALS AND METHODS}

Animals Adult male Mongolian gerbils (Meriones unguiculatus) weighing $60-80 \mathrm{~g}$ were obtained from Central Animal Facility (CAF), NIPER for this study. They were provided with standard diet and water ad libitum and were maintained at $22 \pm 2{ }^{\circ} \mathrm{C}$ and a $12: 12 \mathrm{~h}$ light: dark cycle. All the procedures used in this study were approved by Institutional Animal Ethics Committee (IAEC), NIPER.

Materials Trolox was purchased from Calbiochem Inc., U.S.A. Cresyl violet and malondialdehyde were purchased from Sigma Chemical Company, U.S.A. Rest of the chemicals were of analytical grade and were purchased from commercial suppliers.

Treatment Schedule Gerbils were divided into sham, vehicle-treated ischemic and trolox-treated $(3,10,30 \mathrm{mg} / \mathrm{kg}$ i.p.) ischemic groups. Phosphate buffer saline (pH 7.4) was used as a vehicle for trolox. Trolox was administered $30 \mathrm{~min}$ before occlusion.

Induction of Transient Global Cerebral Ischemia Surgical procedure was followed according to the method described by Colbourne and Corbett. ${ }^{16)}$ Surgery was always carried out between 8:00 am to $1: 00 \mathrm{pm}$. Overnight fasted gerbils were anesthetized with $2.0 \%$ halothane in a gas mixture of $70 \% \mathrm{~N}_{2} \mathrm{O}$ and $30 \% \mathrm{O}_{2}$, followed by maintenance at $1 \%$ halothane (Gas anesthesia system, Harvard Apparatus, U.K.). During occlusion anesthesia was maintained between $0.5-1 \%$ halothane. Rectal temperature was maintained at $37 \pm 0.5^{\circ} \mathrm{C}$ with homeothermic blanket control unit (Harvard Apparatus, U.K.). Ventral neck incision of $2 \mathrm{~cm}$ was made; the bilateral common carotid arteries were separated carefully from vagus nerve and were occluded bilaterally for 5 min with bulldog clamps. Five minutes later, the clamps were removed and reflow was verified visually. Then the neck incision area was sutured and iodine tincture was applied. The gerbils were kept under heating lamp for $2 \mathrm{~h}$ until recovery to prevent post-ischemic hypothermia. Sham-operated non-ischemic animals underwent same surgical procedures, except common carotid arteries were not occluded.

Neurological Symptoms Three hours after ischemia and 
reperfusion gerbils were assessed for neurological symptoms just after recovery, according to the stroke index as described by McGraw with some modification, ${ }^{17}$ ) which is as follows: No $\operatorname{symptom}=0$, Hunched posture or hair roughed $u p=1$, Ptosis $=2$, Circling behaviour $=3$, Splayed-out hind $\operatorname{limb}=4$ and Seizures $=5$. Higher the score, higher was the ischemic insult.

Locomotor Activity Spontaneous locomotor activity was recorded using Opto-Varimex (Columbus, Ohio 43204, U.S.A.), consists of a perspex cage with an observation area of $(43 \mathrm{~cm} \times 43 \mathrm{~cm})$ crisscrossed with 30 infrared light sensitive photocells on horizontal plane, 15 on each axis and each spaced at $2.54 \mathrm{~cm}$. These photocells differentiates ambulatory movement from non-ambulatory movement (such as grooming, scratching). The addition of an optional photocell sensor array, 15 on each axis, located $10 \mathrm{~cm}$ above the floor provides for the monitoring of vertical activity (such as rearing, raised head motions). In the present study total count (accumulation of all beam interruptions, including ambulatory, non-ambulatory and vertical activity) reflected total locomotor activity was taken into consideration. Gerbils were placed individually in each cage and acclimatized for $5 \mathrm{~min}$ before the study. For the time-course study, locomotor activity of the sham-operated, ischemic and drug treated animals was assessed for $15 \mathrm{~min}$ at $1 \mathrm{st}$ and 4 th day of reperfusion. ${ }^{18)}$ Whole experiment was performed under dark sound attenuated and ventilated conditions. The readings were always recorded between 10:00 am to 1:00 pm.

Histological Studies The gerbils were euthanised $4 \mathrm{~d}$ after reperfusion by decapitation. The brains were removed, fixed in $10 \%$ formalin for $24 \mathrm{~h}$ and paraffin embedded. Representative coronal sections $(5 \mu \mathrm{m})$ were obtained with the help of microtome (Leica RM2145, Germany), which included dorsal hippocampus at the level of 1.5 to $1.7 \mathrm{~mm}$ posterior to bregma ${ }^{19)}$ and stained with cresyl violet $(0.5 \%)$. CA1 neurons with blue staining, intact round shaped nuclei were viable neurons, while dark blue stained shrunken neurons with pyknotic cell shape and nuclear condensation were considered damaged. ${ }^{20)}$ Bilateral counts were done of either side of hippocampal region and a total of 8-10 images were captured for each animal for taking average. CA1 cell counting of viable neurons was done at a magnification of $400 \times$ using a CCD camera attached microscope (Leica, Germany) in the medial portion of CA1 of dorsal hippocampus by an observer blind to the treatment condition. The cell counting was expressed as \% of normal cells per mm as compared with sham operated group. ${ }^{21)}$

Lipid Peroxidation Estimation After $4 \mathrm{~h}$ of reperfusion, animals were sacrificed and the brains were removed and rinsed with ice-cold physiological saline. Hippocampal region was separated and homogenised in Tris- $\mathrm{HCl} 0.1 \mathrm{M} \mathrm{pH}$ 7.3 in a ratio of $1: 4$. The homogenate was then centrifuged for $10 \mathrm{~min}$ at $10000 \mathrm{~g}$ at $4{ }^{\circ} \mathrm{C}$ and the resultant supernatant was used for biochemical determinations. Total protein concentration of brain was estimated by the method of Lowry et $a$. $^{22)}$

Lipid peroxidation was measured according to the original method of Ohkawa et al., modified by Zhang et al. ${ }^{23)}$ An aliquot $(100 \mu \mathrm{l})$ of supernatant was added to a reaction mixture containing $100 \mu \mathrm{l}$ of $8.1 \%$ sodium dodecyl sulphate, $750 \mu \mathrm{l}$ of $20 \%$ acetic acid ( $\mathrm{pH} 3.5$ ), $750 \mu \mathrm{l}$ of $0.8 \%$ thiobarbi- turic acid and $300 \mu \mathrm{l}$ of distilled water. Samples were then boiled for $1 \mathrm{~h}$ at $95^{\circ} \mathrm{C}$ and centrifuged at $4000 \mathrm{~g}$ for $10 \mathrm{~min}$. Malondialdehyde (MDA) content was estimated at $532 \mathrm{~nm}$ and quantification was done based on the standard curve using authentic MDA. The MDA content was expressed as $\mu \mathrm{M} / \mathrm{mg}$ of tissue protein.

Data Analysis Statistical analysis was applied using sigma stat 2.0 software. All values were expressed as mean \pm S.D. Neurological scoring and locomotor activity was done by one-way ANOVA followed by Dunnett's multiple comparison tests. Histological analysis and MDA was done by Bonferroni's $t$-test. Difference level at $p<0.05$ was considered statistically significant.

\section{RESULTS}

Effect of Trolox on Neurological Functions and Locomotor Activity Global ischemia produced significant increase in the neurological score and locomotor activity, indicating neurological dysfunction (Figs. 1, 2). Hyperlocomotion was observed on 1 st and 4th day after reperfusion as compared with the sham-operated animals (Fig. 2). Trolox $(30 \mathrm{mg} / \mathrm{kg}$ ) significantly reduced hyperlocomotion and neurological score in ischemic gerbils; however lower doses did not produce significant protection.

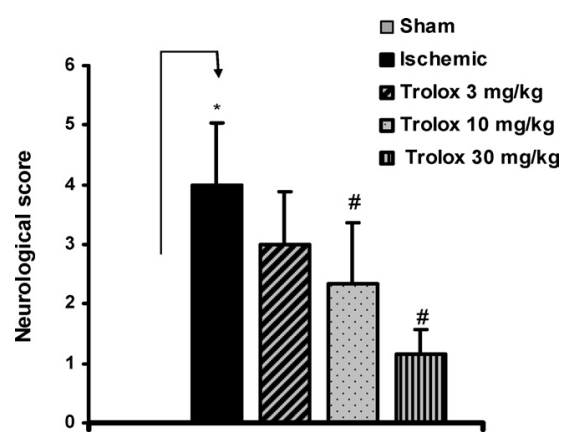

Fig. 1. Neurological Score of Sham-Operated, Ischemic and TroloxTreated Ischemic Gerbils When Subjected to $5 \mathrm{~min}$ of BCAO Assessed $3 \mathrm{~h}$ after Ischemia and Reperfusion

$* p<0.05 v s$. sham-operated group, ${ }^{*} p<0.05 v s$. the ischemic group (tested using ANOVA followed by Dunnett's multiple comparison $t$-test). Each value is expressed as mean \pm S.D. $(n=6-7)$.

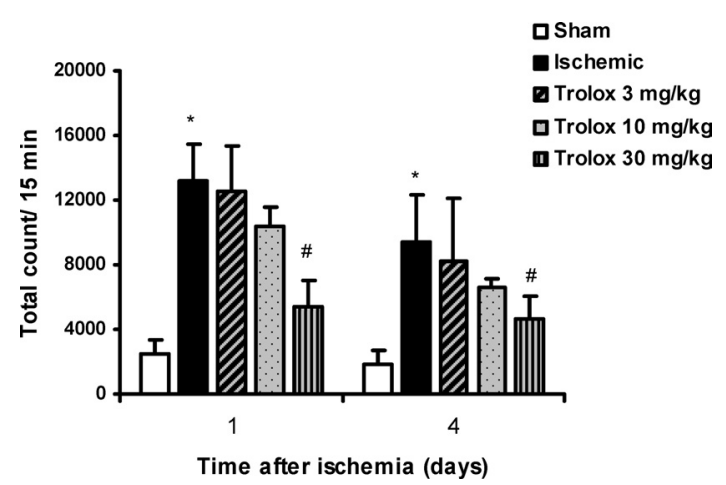

Fig. 2. Locomotor Activity of Sham-Operated, Ischemic and TroloxTreated Ischemic Gerbils When Subjected to $5 \mathrm{~min}$ of BCAO, Assessed on 1st and 4th day after Reperfusion

$* p<0.05 v s$. sham-operated group, $\# p<0.05 v s$. the ischemic group (tested using ANOVA followed by Dunnett's multiple comparison $t$-test). Each value is expressed as mean \pm S.D. $(n=6-7)$. 

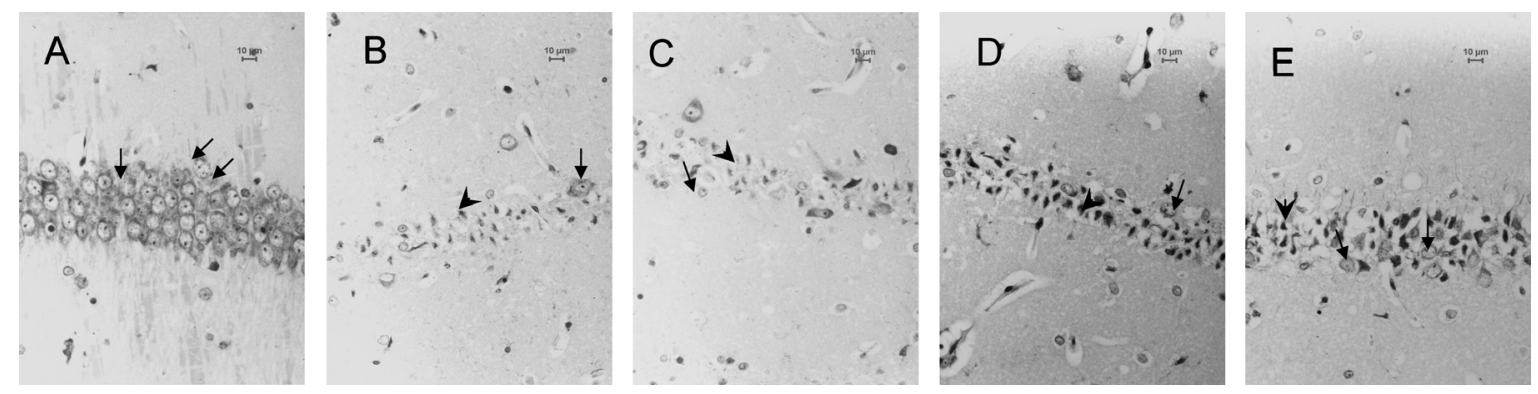

Fig. 3. Neuroprotective Effect of Trolox on the Pyramidal Cell Layer in the Middle CA1 Region in the Hippocampus (A) Sham-Operated, (B) Ischemic, (C) Trolox $3 \mathrm{mg} / \mathrm{kg}$ Treated Ischemic, (D) Trolox $10 \mathrm{mg} / \mathrm{kg}$ Treated Ischemic and (E) Trolox $30 \mathrm{mg} / \mathrm{kg}$ Treated Ischemic Animals

Sections are stained with cresyl violet. Arrows depict intact round shaped blue coloured viable neurons and arrowhead depicts dark blue coloured shrunken damaged neurons. Magnification $400 \times$ and scale bar $10 \mu \mathrm{m}$. Each value is expressed as mean \pm S.D. $(n=6-7)$.

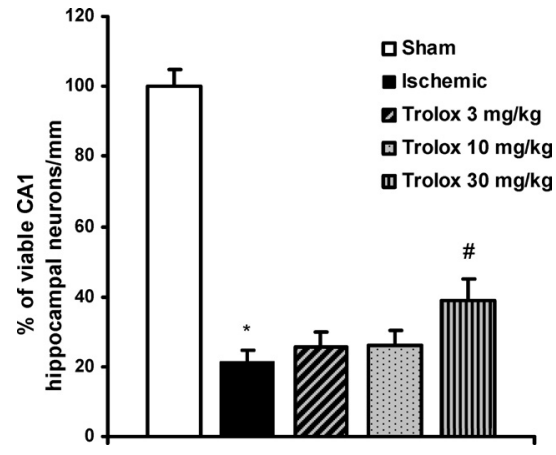

Fig. 4. Histological Analysis of Sham-Operated, Ischemic and TroloxTreated Ischemic Gerbils When Subjected to 5 min of BCAO Assessed 4th day after Reperfusion

$* p<0.05 v s$. sham-operated group, ${ }^{\sharp} p<0.05 v s$. the ischemic group (tested using ANOVA followed by Bonferroni's multiple comparison $t$-test). Each value is expressed as mean \pm S.D. $(n=6-7)$.

Effect of Trolox on Histological Change The microscopic examination of CA1 region of hippocampus indicated that there was a significant $(p<0.05)$ decrease in the number of surviving neurons as compared with the sham-operated animals (Figs. 3, 4). There were shrunken dark blue stained dead cells, while viable neurons were with intact round shape blue colored. Treatment with trolox at $30 \mathrm{mg} / \mathrm{kg}$, significantly $(p<0.05)$ increased the number of surviving neurons.

Effect of Trolox on Lipid Peroxidation MDA levels in hippocampal region were found to be elevated after $4 \mathrm{~h}$ of ischemic reperfusion in gerbils. In ischemic animals the levels of MDA was $25.79 \pm 3.34 \mu \mathrm{m} / \mathrm{mg}$ of protein, as compared with the sham-operated animals $(9.78 \pm 2.64 \mu \mathrm{M} / \mathrm{mg}$ of protein). Elevated levels of MDA in ischemic animals were attenuated $(16.43 \pm 3.32 \mu \mathrm{M} / \mathrm{mg}$ of protein) and $(8.98 \pm 0.89 \mu \mathrm{M} /$ $\mathrm{mg}$ of protein) by trolox 10 and $30 \mathrm{mg} / \mathrm{kg}$, i.p., respectively (Fig. 5).

\section{DISCUSSION}

Global cerebral ischemia occurs during cardiac arrest, cardiopulmonary bypass surgery and other situations that deprive the brain of oxygen and glucose for a short period of time. Approximately $10-20 \%$ of the cardiac arrest patient's show a recovery, others die, or persist in a vegetative state. These patients show neurological injury, delayed hippocampal damage, neurological deficits and impairment of learning and memory. ${ }^{24)}$

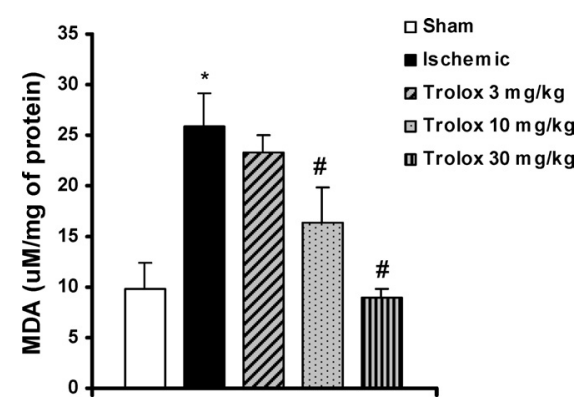

Fig. 5. Malondialdehyde Levels in the Hippocampal Region of Brain of Gerbil in Sham-Operated, Ischemic and Trolox-Treated Gerbils When Subjected to $5 \mathrm{~min}$ of BCAO Assessed $4 \mathrm{~h}$ after Reperfusion

$* p<0.05$ vs. sham-operated group, ${ }^{*} p<0.05$ vs. ischemic group (tested using ANOVA followed by Bonferroni's multiple comparison $t$-test). Each value is expressed as mean \pm S.D. $(n=4)$.

Present study demonstrates the neuroprotective effect of trolox in bilateral carotid arteries occlusion (BCAO) model of global cerebral ischemia in gerbils. Mongolian gerbils were selected for inducing global ischemia. Gerbil shows features of global cerebral ischemia just after brief occlusion of common carotid arteries, as they lack posterior communicating arteries between the carotid arteries and vertebral arteries, which constitute an incomplete Circle of Willis. ${ }^{25)}$ $\mathrm{BCAO}$ for $5 \mathrm{~min}$ in gerbils resulted in selective loss of pyramidal neurons in the CA1 area of hippocampus within $96 \mathrm{~h}$ to become apparent morphologically. There was substantial hippocampal neuronal death $(80-85 \%)$ in ischemic animals as compared with the sham-operated animals. Ischemic animals showed hyperlocomotion on $1 \mathrm{st}$ and 4th day of reperfusion. This was found to be consistent with the findings stating that on the 1stday after reperfusion, ischemia induced increase in locomotor activity is prominent, following 2 nd day it starts decreasing. ${ }^{26)}$ Thus based on this analysis the 1st and 4th day was selected for assessment of effect of ischemic insult on gerbil's locomotor activity.

We have observed neuroprotective effect of trolox $(30 \mathrm{mg} /$ $\mathrm{kg}$ ) on hippocampal CA1 neurons, as evident from significant increase $(17.54 \%)$ in the number of surviving neurons. Hyperlocomotion and neurological deficits in ischemic animals were also attenuated by trolox. We have observed a correlation between hippocampal cell death and locomotor hyperactivity. Similar correlation in hippocampal cell damage and spatial learning deficit has also been reported. ${ }^{27,28)}$

Neuroprotective effect of trolox is further supported by its 
protective effect in amyloid $\beta$-mediated neurotoxicity, ${ }^{29)}$ and interleukin (IL-1 $\beta$ ) induced neurodegeneration. ${ }^{30)}$ In addition to protective effects in neurotoxicity models, trolox counteracted the toxic effects of S-morpholinosydnonimine (SIN-1), a peroxynitrite donor in lung epithelial cells, ${ }^{31)}$ and in arrhythmias in isolated heart preparations. ${ }^{32}$ )

Consistent with the earlier reports, we have also observed significant increase in the level of MDA in ischemic animals indicating oxidative stress. ${ }^{33)}$ Trolox dose dependently inhibited MDA levels in ischemic gerbils. Trolox at the dose level $30 \mathrm{mg} / \mathrm{kg}$ completely inhibited the increased levels of MDA after global ischemia. This indicates antioxidant effects of trolox. Trolox $10 \mathrm{mg} / \mathrm{kg}$ showed only partial inhibition however lower dose $3 \mathrm{mg} / \mathrm{kg}$ did not inhibit MDA level.

Despite complete inhibition of MDA, protection at CA1 neuronal damage was partial. This may be because of involvement of multiple pathways in global cerebral ischemia-reperfusion injury. After an ischemic-reperfusion (IR) injury, neuronal cell death cascade continues for several days. The delayed neuronal cell death is a multi-faceted complex cascade of events. Oxidative stress is one of the key player of this neuronal cell death cascade. ROS leads to neuronal death by oxidizing various micro and macro component of the cellular system such as lipid, proteins and nucleotides etc. Lipid peroxidation has been suggested to play an important role in the pathogenesis of delayed neuronal damage in global ischemia. ${ }^{34,35)}$ ROS attacks on biological membrane, leading to oxidative destruction of polyunsaturated fatty acids. These polyunsaturated fatty acids are rich in brain, leading to oxygen free radical induced lipid peroxidation. Apart from lipid peroxidation several other biological processes have been proposed to contribute to the delayed neuronal cell death including exitotoxicity, ${ }^{36)}$ ionic imbalance, mitochondrial dysfunctions, ${ }^{37,38)}$ poly (ADP-ribose) polymerase overactivation, ${ }^{39)}$ inflammatory reaction, ${ }^{40,41)}$ the activation of mitogen activated protein kinases, ${ }^{38,42)}$ death associated protein kinases ${ }^{43)}$ and apoptosis ${ }^{44)}$ etc. also plays a role in this cascade.

In addition to our study other studies have shown inhibition of lipid peroxidation in rat brain homogenates by trolox. ${ }^{45}$ ) Trolox decreased cyto- and geno-toxicity in yeast cells. It lowered intracellular oxidation and decreased intracellular peroxides formation, and increased $\mathrm{H}_{2} \mathrm{O}_{2}$ degradation and superoxide quenching yeast extract ability. ${ }^{46)}$ Trolox and other vitamin $\mathrm{E}$ analogues have shown peroxynitrite scavenging activity at the concentration range of 0.015 $5 \mu \mathrm{M}$ in $\mathrm{Cu}^{2+}$-induced experimental model of lipid oxidation of plasma. ${ }^{4748)}$ Rat thymocytes pretreated with trolox immediately after exposure to peroxynitrite showed decreased thiobarbituric acid reactive substances and DNA cross-linking. This study suggested protection against peroxynitrite mediated oxidative stress and apoptosis. ${ }^{49)}$ Trolox has been reported to possess scavenging of peroxyradicals, better than its parent compound. It protected human myocytes and hepatocytes against in situ generated oxyradicals. ${ }^{13)}$

Trolox is a synthetic derivative of tocopherol with improved access to the hydrophilic compartment of cells. It is a potent free radicals scavenger than tocopherol. Trolox produced better results than melatonin and lipoic-acid in reducing lipid peroxidation induced by hydrogen peroxide $(10 \mathrm{~mm})$ and ferrous ammonium sulfate $(5 \mu \mathrm{M})$ in gerbil brain ho- mogenate. In hydrogen peroxide induced lipid peroxidation the $\mathrm{IC}_{50}$ values of antioxidants were: trolox $(37.08 \mu \mathrm{M})$, lipoic acid $(7.88 \mathrm{~mm})$, and melatonin $(19.11 \mathrm{~mm})$, while in ferrous ion-induced lipid peroxidation the $\mathrm{IC}_{50}$ values were: trolox $(75.65 \mu \mathrm{M})$, lipoic acid $(7.63 \mathrm{~mm})$, and melatonin $(15.48$ $\mathrm{mm}){ }^{50)}$ Trolox was superior as compared to melatonin in preventing lipid peroxidation and creatine kinase activity, a selective marker of protein modification in oxidative stress, in ferrous/ascorbate induced oxidative stress in rat brain homogenate. ${ }^{51)}$ Suppression of lipid peroxidation was 20 times less with melatonin and alpha-lipoic acid, in comparison to trolox, in rat brain homogenate. ${ }^{52}$ Trolox was found to be more potent than vitamin $\mathrm{E}$ in cardiac ischemic-reperfusion injury model. ${ }^{53)}$ Moreover trolox, has been shown to function more efficiently in acute oxidative stress conditions like hepatic ischemic reperfusion injury. This rapid and efficient antioxidant property of trolox was attributed due to its enhanced water solubility as compared with alpha-tocopherol. ${ }^{54)}$

In conclusion, trolox offered significant neuroprotection in BCAO model of global cerebral ischemia in gerbil. Neuroprotective effect of trolox was associated with reduction in hippocampal lipid peroxidation. This study suggests beneficial effects of trolox in global cerebral ischemia.

Acknowledgements This study was supported by grant from NIPER project (NP-035) to Dr. S. S. Sharma. Authors would like to thank Mr. Ravinder Kaundal for helping in revising the manuscript.

\section{REFERENCES}

1) Turley K. R., Toledo-Pereyra L. H., Kothari R. U., J. Invest. Surg., 18, $207-218$ (2005)

2) Kirino T., Tamura A., Sano K., Acta Neuropathol. (Berl.), 64, 139147 (1984).

3) Wang Q., Xu J., Rottinghaus G. E., Simonyi A., Lubahn D., Sun G. Y., Sun A. Y., Brain Res., 958, 439-447 (2002).

4) Kirino T., Brain Res., 239, 57-69 (1982).

5) Rodrigo J., Fernandez A. P., Serrano J., Peinado M. A., Martinez A., Free Radic. Biol. Med., 39, 26-50 (2005).

6) Denicola A., Radi R., Toxicology, 208, 273-288 (2005)

7) Marla S. S., Lee J., Groves J. T., Proc. Natl. Acad. Sci. U.S.A., 94, $14243-14248$ (1997).

8) Lee S., Suh S., Kim S., Neurosci. Lett., 287, 191-194 (2000).

9) Gupta S., Kaul C. L., Sharma S. S., Neurol. Res., 26, 103-107 (2004).

10) Sharma S. S., Munusamy S., Thiyagarajan M., Kaul C. L., J. Neurosurg., 101, 669-675 (2004).

11) Thiyagarajan M., Kaul C. L., Sharma S. S., Br. J. Pharmacol., 142, 899-911 (2004).

12) Chen K., Chen J., Li D., Zhang X., Mehta J. L., Hypertension, 44, 655-661 (2004)

13) Eum H. A., Lee S. M., Br. J. Pharmacol., 142, 35-42 (2004).

14) Tan S., Zhou F., Nielsen V. G., Wang Z., Gladson C. L., Parks D. A., J. Neuropathol. Exp. Neurol., 58, 972-981 (1999).

15) Lamarche F., Signorini-Allibe N., Gonthier B., Barret L., Alcohol, 33, $127-138$ (2004).

16) Colbourne F., Corbett D., Brain Res., 654, 265-272 (1994).

17) McGraw C. P., Arch. Neurol., 34, 334-336 (1977).

18) Katsuta K., Umemura K., Ueyama N., Matsuoka N., Eur. J. Pharmacol., 467, 103-109 (2003).

19) Loskoto W. J., Lomax P., Verity M. A., "A Stereotaxic Atlas of the Mongolian Gerbil Brain (Meriones unguiculatus)," Ann Arbor Science Publishers, Ann Arbor, MI, 1975.

20) Cross A. J., Jones J. A., Baldwin H. A., Green A. R., Br. J. Pharmacol., 104, 406-411 (1991).

21) Zhu H., Meloni B. P., Moore S. R., Majda B. T., Knuckey N. W., Brain 
Res., 1014, 53-60 (2004).

22) Lowry O. H., Rosebrough N. J., Farr A. L., Randall R. J., J. Biol. Chem., 193, 265-275 (1951).

23) Zhang D. L., Zhang Y. T., Yin J. J., Zhao B. L., J. Neurochem., 90, $211-219$ (2004).

24) Lim C., Alexander M. P., LaFleche G., Schnyer D. M., Verfaellie M., Neurology, 63, 1774-1778 (2004).

25) Kirby B. P., Shaw G. G., Brain Res., 1011, 74-83 (2004).

26) Colbourne F., Auer R. N., Sutherland G. R., Brain Res., 803, 69-78 (1998).

27) Block F., Schwarz M., Pharmacol. Biochem. Behav., 56, 755-761 (1997).

28) Kitagawa K., Matsumoto M., Oda T., Niinobe M., Hata R., Handa N., Fukunaga R., Isaka Y., Kimura K., Maeda H., Mikoshiba K., Kamada T., Neuroscience, 35, 551-558 (1990)

29) Quintanilla R. A., Munoz F. J., Metcalfe M. J., Hitschfeld M., Olivares G., Godoy J. A., Inestrosa N. C., J. Biol. Chem., 280, 11615-11625 (2005).

30) Radesater A. C., Johansson S., Oberg C., Luthman J., Neurotox. Res., 5, 433-442 (2003).

31) Offer S., Eliraz A., Fink G., Stark A. H., Madar Z., Pharmacology, 73, $155-161(2005)$

32) Betters J. L., Criswell D. S., Shanely R. A., Van Gammeren D., Falk D., Deruisseau K. C., Deering M., Yimlamai T., Powers S. K., Am. J. Respir. Crit. Care Med., 170, 1179-1184 (2004).

33) Cuzzocrea S., Mazzon E., Costantino G., Serraino I., Dugo L., Calabro G., Cucinotta G., De Sarro A., Caputi A. P., Br. J. Pharmacol., 130, 1219-1226 (2000).

34) Gutteridge J. M., Halliwell B., Trends Biochem. Sci., 15, 129-135 (1990).

35) Kim H. J., Lee S. R., Moon K. D., Phytother. Res., 17, 909-912 (2003).

36) Caccamo D., Campisi A., Curro M., Li Volti G., Vanella A., Ientile R., Amino Acids, 27, 373-379 (2004).

37) Hetz C., Vitte P. A., Bombrun A., Rostovtseva T. K., Montessuit S.
Hiver A., Schwarz M. K., Church D. J., Korsmeyer S. J., Martinou J. C., Antonsson B., J. Biol. Chem., 280, 42960 - 42970 (2005).

38) Carboni S., Antonsson B., Gaillard P., Gotteland J. P., Gillon J. Y., Vitte P. A., J. Neurochem., 92, 1054-1060 (2005).

39) Chiarugi A., Pharmacol. Res., 52, 15-24 (2005).

40) Block M. L., Hong J.-S., Prog. Neurobiol., 76, 77-98 (2005).

41) Stoll G., Jander S., Schroeter M., Prog. Neurobiol., 56, 149-171 (1998).

42) Guan Q. H., Pei D. S., Zhang Q. G., Hao Z. B., Xu T. L., Zhang G. Y., Brain Res., 1035, 51-59 (2005).

43) Shamloo M., Soriano L., Wieloch T., Nikolich K., Urfer R., Oksenberg D., J. Biol. Chem., 280, 42290- 42299 (2005).

44) Siegelin M. D., Kossatz L. S., Winckler J., Rami A., Neurochem. Int., 46, 41-51 (2005).

45) Hall E. D., Pazara K. E., Braughler J. M., Linseman K. L., Jacobsen E. J., Stroke, 21, III83-III87 (1990).

46) Raspor P., Plesnicar S., Gazdag Z., Pesti M., Miklavcic M., Lah B., Logar-Marinsek R., Poljsak B., Cell Biol. Int., 29, 57-63 (2005).

47) Galli F., Piroddi M., Lannone A., Pagliarani S., Tomasi A., Floridi A., Int. J. Vitam. Nutr. Res., 74, 362-373 (2004).

48) Koufaki M., Calogeropoulou T., Detsi A., Roditis A., Kourounakis A P., Papazafiri P., Tsiakitzis K., Gaitanaki C., Beis I., Kourounakis P. N., J. Med. Chem., 44, 4300-4303 (2001).

49) Salgo M. G., Pryor W. A., Arch. Biochem. Biophys., 333, 482-488 (1996).

50) Lee S. R., Im K. J., Suh S. I., Jung J. G., Phytother. Res., 17, 206-209 (2003).

51) Horakova L., Ondrejickova O., Bachrata K., Vajdova M., Gen. Physiol. Biophys., 19, 195-205 (2000).

52) Rauhala P., Chiueh C. C., Ann. N.Y. Acad. Sci., 899, 238-254 (2000).

53) Sagach V. F., Scrosati M., Fielding J., Rossoni G., Galli C., Visioli F. Pharmacol. Res., 45, 435-439 (2002).

54) Wu T. W., Hashimoto N., Au J. X., Wu J., Mickle D. A., Carey D., Hepatology, 13, 575-580 (1991). 